Research Article

\title{
Deformation Responses and Mechanical Mechanism of Existing Tunnel due to New Building Construction
}

\author{
Haifeng Guo $\mathbb{D}^{1,2}$ Dong $M a \mathbb{D}^{1},{ }^{1}$ and Aijun Yao $\mathbb{D}^{2}$ \\ ${ }^{1}$ China Railway 16th Bureau Group Co., Ltd., Beijing 100018, China \\ ${ }^{2}$ The Key Laboratory of Urban Security and Disaster Engineering, Ministry of Education, Beijing University of Technology, \\ Beijing 100124, China \\ Correspondence should be addressed to Haifeng Guo; ghf_doudou@sina.com
}

Received 16 October 2020; Revised 30 December 2020; Accepted 20 January 2021; Published 4 February 2021

Academic Editor: Pier Paolo Rossi

Copyright (c) 2021 Haifeng Guo et al. This is an open access article distributed under the Creative Commons Attribution License, which permits unrestricted use, distribution, and reproduction in any medium, provided the original work is properly cited.

\begin{abstract}
This study mainly investigated the variation law and mechanical mechanism of surrounding earth pressure and deformation of an existing tunnel, caused by dewatering, foundation excavation, building loading, and groundwater recovery. According to different dewatering schemes, two modes were established: nonisolated dewatering unloading-loading mode and isolated dewatering unloading-loading mode. Through large-scale similar materials model test, the variation law of deformation and surrounding earth pressure of adjacent tunnel under complex unloading-loading conditions was preliminarily revealed. Based on the size of the prototype project, the test results were further verified by the numerical simulation. The mechanical mechanism of tunnel deformation in different construction stages was analyzed after the comparative study. The results show that the tunnel structure deformation, vertical and horizontal displacement, and torsion occur in the process of building construction. In the nonisolated dewatering unloading-loading mode, the decrease or rise of the groundwater level significantly reduces (maximum 27.85\%) or increases (maximum 35.19\%) the surrounding earth pressure of the tunnel. The decrease or increase of the horizontal total stress was much greater than that of the vertical total stress, which leads to the deformation of tunnel structure. The vertical displacement of the tunnel is generally settlement, which mainly occurs in the stage of dewatering and building loading, accounting for $83.21 \%-$ $100.00 \%$ and $25.11 \%-40.34 \%$ of the total settlement, respectively. In the stage of foundation pit excavation and groundwater recovery, the tunnel rises. In the horizontal direction, the tunnel moves towards the foundation pit, mainly in the excavation stage, accounting for $82.77 \%-86.30 \%$ of the maximum value. Due to the uneven change of displacement field and stress field of soil outside the foundation pit, the tunnel torsion occurs. In the isolated dewatering unloading-Loading mode, the change of groundwater has little effect on the tunnel. In the stage of excavation and construction load, the variation law of tunnel surrounding earth pressure and deformation is similar in the two modes.
\end{abstract}

\section{Introduction}

As the lifeline project of the modern city, the subway significantly alleviates the congestion of urban ground traffic. However, due to its structural characteristics, it is sensitive to the deformation of the surrounding soil. The construction of high-rise buildings near existing subway tunnels often leads to the heave [1-3] or the subsidence [4] of the tunnel, the uneven bending deformation along the longitudinal direction of the tunnel [5], the separation of the bottom of track bed from the lining structure, and the cracks and breakage of segments [6-8], etc., which bring significant safety risks to the structure and normal operation of existing subway tunnels. Therefore, the deformation characteristics of the existing subway tunnel during the construction of buildings are very important. At present, many researchers have studied this problem. Most of the researchers mainly studied the influence of foundation pit excavation on the deformation of the adjacent tunnel using various methods, including model tests [9-13], numerical simulations [2, 14-21], analytical methods [22-27], and field monitoring $[5,28-32]$. The main contents of the study are the excavation shape $[33,34]$, relative distance between the 
excavation pit and the tunnel [1, 19], construction method [3, 18], soil properties [20,35], and the tunnel protection measures $[36,37]$, etc.

Only a few researchers studied the effects of the loading at the bottom of the foundation pit or ground surface on the tunnel. Dolezalova [38] analyzed the impact of foundation pit excavation and loading in the base of the pit on the tunnel. Wang et al. [39] presented an analytical method to predict the displacement and stress around shallow tunnels due to surcharge loadings.

The dewatering of the foundation pit inevitably affects the nearby tunnel. However, most researchers focus on the law of surface subsidence caused by dewatering [40-42], or the impact of dewatering on underground piles [43]. The research on the impact of the dewatering on the adjacent tunnel is relatively few.

The impact of building construction on the surrounding environment is continuous, including foundation pit dewatering, foundation pit excavation, building construction, and groundwater recovery, and the impact on the surrounding environment can only be ended after all the construction is completed. At present, most of the researches are focused on single working condition, which cannot reflect the whole process of the influence of buildings on adjacent tunnels.

Therefore, based on a foundation pit project near to a metro tunnel in eastern Beijing, China, two similar material simulation tests and corresponding numerical simulations were carried out under different conditions to study the deformation response and its mechanical mechanism of an existing tunnel under complex unloading-loading construction.

\section{Model Test}

2.1. Engineering Scenario. The prototype project of the model test locates in the west of Beijing Metro Line 10 (China), as shown in Figure 1. The shield tunnel is $6 \mathrm{~m}$ in outer diameter and $5.4 \mathrm{~m}$ in inner diameter. The lining is made by C50 precast concrete segment, which is $0.3 \mathrm{~m}$ in thickness and $1.2 \mathrm{~m}$ in width. The excavation depth of the foundation pit is $15 \mathrm{~m}$, and the tunnel is only $5.1 \mathrm{~m}$ away from the project. The foundation pit is supported by the soil nailing wall (upper part), diaphragm wall, and prestressed anchor cable (lower part). The specific characteristics of the soil strata are summarized in Table 1. The groundwater situation is shown in Table 2.

2.2. Similarity Ratio. Considering the size of prototype project and model box, the accuracy of measuring apparatus and the other test conditions in order to ensure that the influence of boundary effect on the data was minimized [44], the geometric similarity ratio was determined as $15: 1$, and the unit weight similarity ratio was determined as $1: 1$. According to the geometric, equilibrium, and physical equations $[45,46]$, equation (1) can be deduced. If the dimension is the same, the similarity ratio is the same, and the similarity ratio of nondimensional physical quantity is 1 .
Therefore, the similarity ratios of the other physical quantities can be deduced, as shown in Table 3 .

$$
\begin{aligned}
& C_{\sigma}=C_{\gamma} C_{L}, \\
& C_{\delta}=C_{\varepsilon} C_{L}, \\
& C_{\sigma}=C_{\varepsilon} C_{E} .
\end{aligned}
$$

2.3. Model Container and Similar Material. The large model test container was $3000 \mathrm{~mm} \times 1000 \mathrm{~mm} \times 2000 \mathrm{~mm}$ in dimension, composed of tempered glass composite plates, columns, stiffening ribs, ring beams, etc., as shown in Figure 2. To simulate the soil, the river sand and the iron powder were selected as aggregate. The river sand mainly provided the basic cohesion and internal friction angle of the simulation material, and the iron powder mainly increased the weight. The lime and gypsum were selected as adhesives, which mainly changed the cohesion and internal friction angle of the soil in different stratum. Through the proportioning test, the cohesion, internal friction angle, and elastic modulus met the similarity ratio. The material proportion of each stratum is shown in Table 4 . In the numerical simulation, the diaphragm wall, the raft foundation, and the tunnel were all elastic materials. Therefore, the acrylic glass was selected for simulation, whose elastic modulus (reduced according to the similarity ratio) was similar. According to the main characteristics of the prestressed anchor cable, it was simulated by the wire rope with quick-drying cement. In the test preparation stage, the wire rope was placed and quick-drying cement was poured to simulate the anchorage section. In the test stage, after the foundation pit was excavated to the position of anchor cable, the wire rope was tensioned by electronic spring scale. The wells were simulated by PVC tubes.

2.4. Test Scheme. In the model test, the support form was simplified as the diaphragm wall with the prestressed anchor cable. The iron weights were used to simulate the building load. Twelve weights were loaded at the mat foundation every time, which was the load of two floors of construction corresponding to the prototype. The groundwater condition was simplified to phreatic water. The initial water level was $-0.5 \mathrm{~m}$. After the dewatering, the groundwater level was lower than the pit base $0.07 \mathrm{~m}$, which was approximately equal to $1 \mathrm{~m}$ in the prototype project.

The layouts of the support structure are as shown in Figure 3 . The scheme 1 is nonisolated dewatering unloadingloading mode, and the scheme 2 is isolated dewatering unloading-loading mode. In scheme 1 , the diaphragm wall did not separate the seepage field inside and outside the foundation pit. In the draining stage, the self-priming pumps pumped groundwater from the PVC tubes on the left side. Meanwhile, to simulate the supplement of natural groundwater, four pumps pumped water into the PVC tubes on the right side. There were piezometric tubes to observe the water level. In scheme 2 , the diaphragm wall reached the bottom of the container to separate the seepage field inside and outside the foundation pit. 


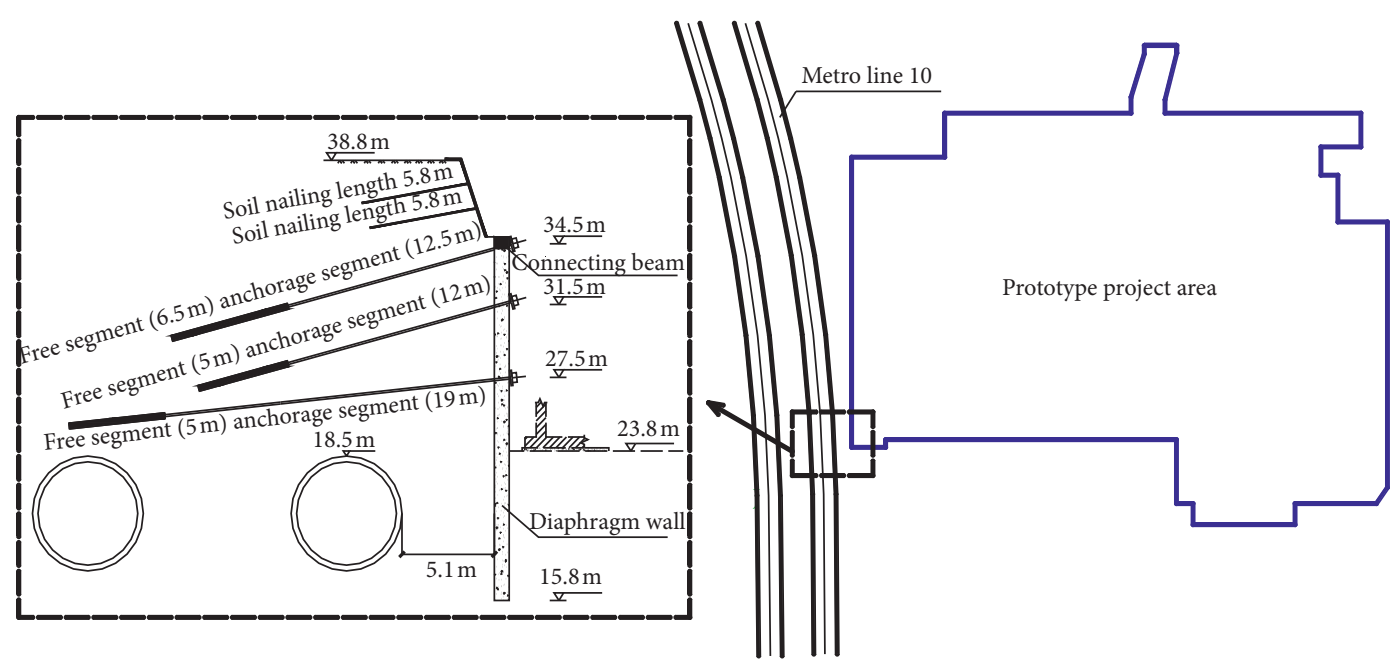

Figure 1: Plane position map of excavation and tunnel.

TABLE 1: Soil properties.

\begin{tabular}{|c|c|c|c|c|c|c|}
\hline Type of soil & $\begin{array}{l}\text { Thickness } \\
\text { (m) }\end{array}$ & $\begin{array}{l}\text { Unit weight } \\
\left(\mathrm{kN} / \mathrm{m}^{3}\right)\end{array}$ & $\begin{array}{c}\text { Compression modulus } \\
(\mathrm{MPa})\end{array}$ & Cohesion $(\mathrm{kPa})$ & $\begin{array}{c}\text { Internal friction } \\
\text { angle }\left({ }^{\circ}\right)\end{array}$ & Poisson ratio \\
\hline Miscellaneous fill & 2.0 & 18.5 & 7.0 & 10 & 15.0 & 0.36 \\
\hline Clayey silt I & 5.2 & 21.6 & 7.7 & 21 & 20.7 & 0.25 \\
\hline Silty clay & 12.2 & 20.7 & 9.7 & 28.7 & 20.6 & 0.26 \\
\hline Clayey silt II & 2.8 & 20.6 & 18.7 & 30 & 23.0 & 0.25 \\
\hline Medium sand & 3.2 & 21.0 & 30.0 & 0 & 30.0 & 0.27 \\
\hline Pebbles & 4.5 & 22.0 & 55.0 & 0 & 35.0 & 0.23 \\
\hline
\end{tabular}

TABLE 2: Groundwater situation.

\begin{tabular}{lccccc}
\hline Type of water & Phreatic water & Interlayer water & Interlayer water & Confined water & Confined water \\
\hline Water level depth $(\mathrm{m})$ & $5.90-10.80$ & $17.80-18.40$ & $20.70-23.10$ & $24.30-25.00$ & $28.80-29.20$ \\
\hline
\end{tabular}

TABLE 3: Similarity ratio of physical quantities.

\begin{tabular}{|c|c|c|c|c|c|c|}
\hline Parameter & Geometry, $C_{L}$ & Displacement, $C_{\delta}$ & Elastic modulus, $C_{E}$ & Cohesion, $C_{C}$ & Unit weight, $C_{\gamma}$ & Internal friction angle, $C_{\varphi}$ \\
\hline Ratio & $15: 1$ & $15: 1$ & $15: 1$ & $15: 1$ & $1: 1$ & $1: 1$ \\
\hline
\end{tabular}

2.5. Measuring Equipment. The tunnel displacement was measured by the guyed displacement sensor (range: 0-100 mm, accuracy: $0.01 \mathrm{~mm}$ ). The miniature soil pressure cell was applied to measure the surrounding earth pressure (range: $100 \mathrm{kPa}$ ). Sixteen soil pressure cells were set in the middle of the outer wall of the tunnel, and two guyed displacement sensors were set on the right side and above the middle section of the tunnel, respectively, to measure the horizontal and vertical displacement, as shown in Figure 3.

2.6. Model Test Process. The tunnel and the diaphragm wall were conducted as the soil was put in the container. The test started when all data were stable. The model test process is shown in Table 5.

2.7. Model Test Results and Analysis. The positive value of the vertical displacement represents that the tunnel rises, whereas the negative value means that the tunnel sinks. The positive value of the horizontal displacement represents that the tunnel moves towards the foundation pit, whereas the negative value represents that the tunnel moves away from the foundation pit. The value of the earth pressure is always positive, and it represents the soil pressure cell is pressed. This section only discusses the variation law of surrounding earth pressure and displacement of the tunnel under various conditions, and its mechanical mechanism is discussed in Section 4.

2.7.1. Variation Law of Surrounding Earth Pressure on the Tunnel. As shown in Figure 4, the earth pressure around the tunnel is large at the top and bottom and small on the middle sides.

In scheme 1, after the foundation pit dewatering, the surrounding earth pressure at each measuring point of the tunnel is significantly reduced. The maximum decrease value 


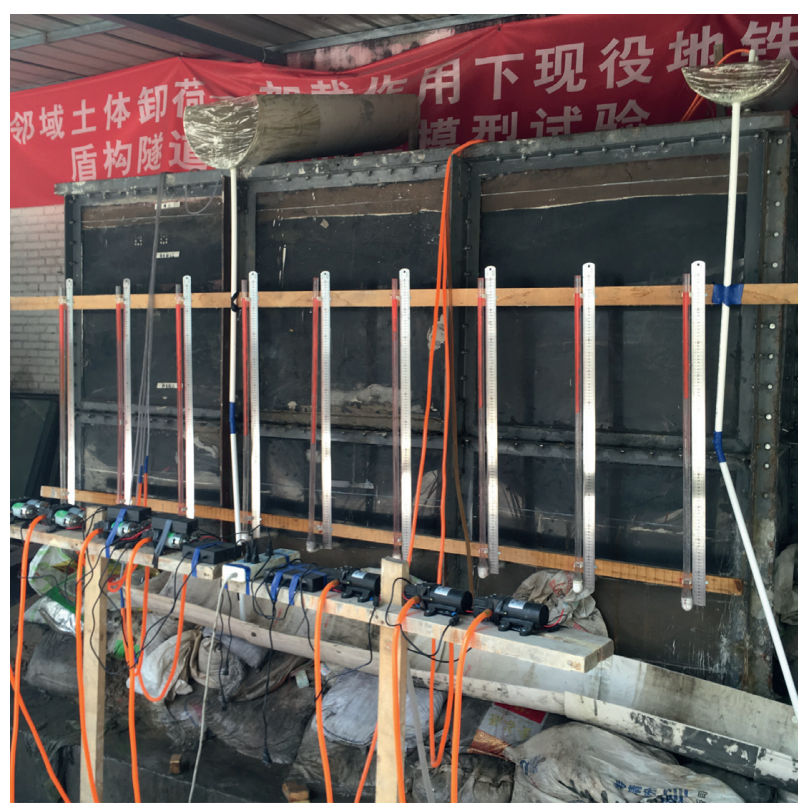

FIgURE 2: Model container of similar test.

TABLE 4: Material proportion of test soil.

\begin{tabular}{lc}
\hline Type of soil & Ratio of material \\
\hline Miscellaneous fill & Sand $=1$ \\
Clayey silt I & Sand:iron powder:lime:gypsum $=19: 8: 2: 1$ \\
Silty clay & Sand:iron powder:lime:gypsum $=19: 8: 1: 1$ \\
Clayey silt II & Sand:iron powder:lime:gypsum $=19: 8: 2: 1$ \\
Medium sand & Sand $=1$ \\
Pebbles & Sand:iron powder $=20: 1$ \\
\hline
\end{tabular}

$(52.26 \mathrm{kPa})$ was located at measuring point 7 , which was $28.01 \%$ of the initial value. The decrease of the horizontal total stress (measuring point $5: 32.00 \mathrm{kPa}$ ) was much greater than that of the vertical total stress (measuring point 1: $8.30 \mathrm{kPa}$ ). When the foundation pit is excavated, the surrounding earth pressure at the measuring point is slightly reduced, and equally, the reduction of the side measuring points is larger. After the building loading, the surrounding earth pressure of the measuring points increases slightly. When the groundwater recovers, the surrounding earth pressure of each measuring point increases obviously. The increase of the horizontal total stress (measuring point 5 : $19.53 \mathrm{kPa}$ ) was much greater than that of the vertical total stress (measuring point $1: 5.78 \mathrm{kPa}$ ).

In scheme 2, because the diaphragm wall separates the seepage field inside and outside the foundation pit, the change of water level in the foundation pit has little influence on the surrounding earth pressure on the tunnel. The impact of foundation pit excavation and building loading on the distribution characteristics of surrounding earth pressure is similar to that of scheme 1 .

2.7.2. Variation Law of the Tunnel Displacement. The variation law of tunnel horizontal displacement in the two schemes is similar, as shown in Figure 5. After dewatering, the tunnel almost has no horizontal displacement. When the foundation pit is excavated, the tunnel moves towards the foundation pit, and with the increase of the excavation depth, the horizontal displacement of the tunnel gradually increases. During the loading stage, it continues to move towards the foundation pit. After groundwater recovery, the tunnel has almost no horizontal displacement. In the two schemes, the decrease or rise of groundwater has little effect on the horizontal displacement of the tunnel. The horizontal displacement of the tunnel $(10.35 \mathrm{~mm})$ is more significant than the vertical displacement $(-2.55 \mathrm{~mm})$. The horizontal displacement is mainly produced in the foundation pit excavation stage, accounting for $86.25 \%$ of the maximum value, which indicates that the foundation pit excavation has a greater impact on the horizontal displacement of the tunnel.

In the vertical direction, according to the effective stress principle, after dewatering, the pore water pressure of the soil between the original water level and the dewatering water level decreases, and the effective stress increases, and the consolidation compression occurs. Therefore, in scheme 1, the tunnel produces a small amount of settlement, i.e., $-2.55 \mathrm{~mm}$, accounting for $54.84 \%$ of the maximum value. However, in scheme 2, as the diaphragm wall separates the seepage field inside and outside the foundation pit, the dewatering in the foundation pit has little influence on the seepage field outside the pit. As shown in Figure 4, the surrounding earth pressure on the tunnel does not change, so there is almost no vertical displacement of the tunnel. The law of the two schemes is basically the same in the stage of foundation pit excavation and building loading, which indicates that the existing mode of groundwater has no apparent influence on the foundation pit excavation and building loading. When the foundation pit is excavated, with the increase of the excavation depth of the foundation pit, the tunnel begins to heave slightly, whereas when the pit base reaches the buried depth of the top of the tunnel, the tunnel gradually begins to sink. When the building is loaded, the tunnel sinks slightly, and the vertical displacement of the tunnel increases gradually with the increase of the building load. When the water level recovers to the initial water level, the tunnel in scheme 1 floats slightly, while the tunnel in scheme 2 has almost no vertical displacement.

The test simulates the interval between the completion of foundation pit excavation and the loading of buildings, i.e., step 14. As shown in Figure 5, the tunnel displacement has an obvious leap. It shows that the time effect of foundation pit excavation is pronounced. The interval time should be shortened as far as possible in the actual project to reduce the impact of foundation pit excavation on the surrounding environment.

\section{Numerical Simulation}

Although the model test has various advantages, it is still unable to avoid the constraints of experimental conditions. Therefore, to compare and verify the model test, two groups of numerical simulation analyses were carried out by the three-dimensional finite-difference simulation software FLAC3D. 

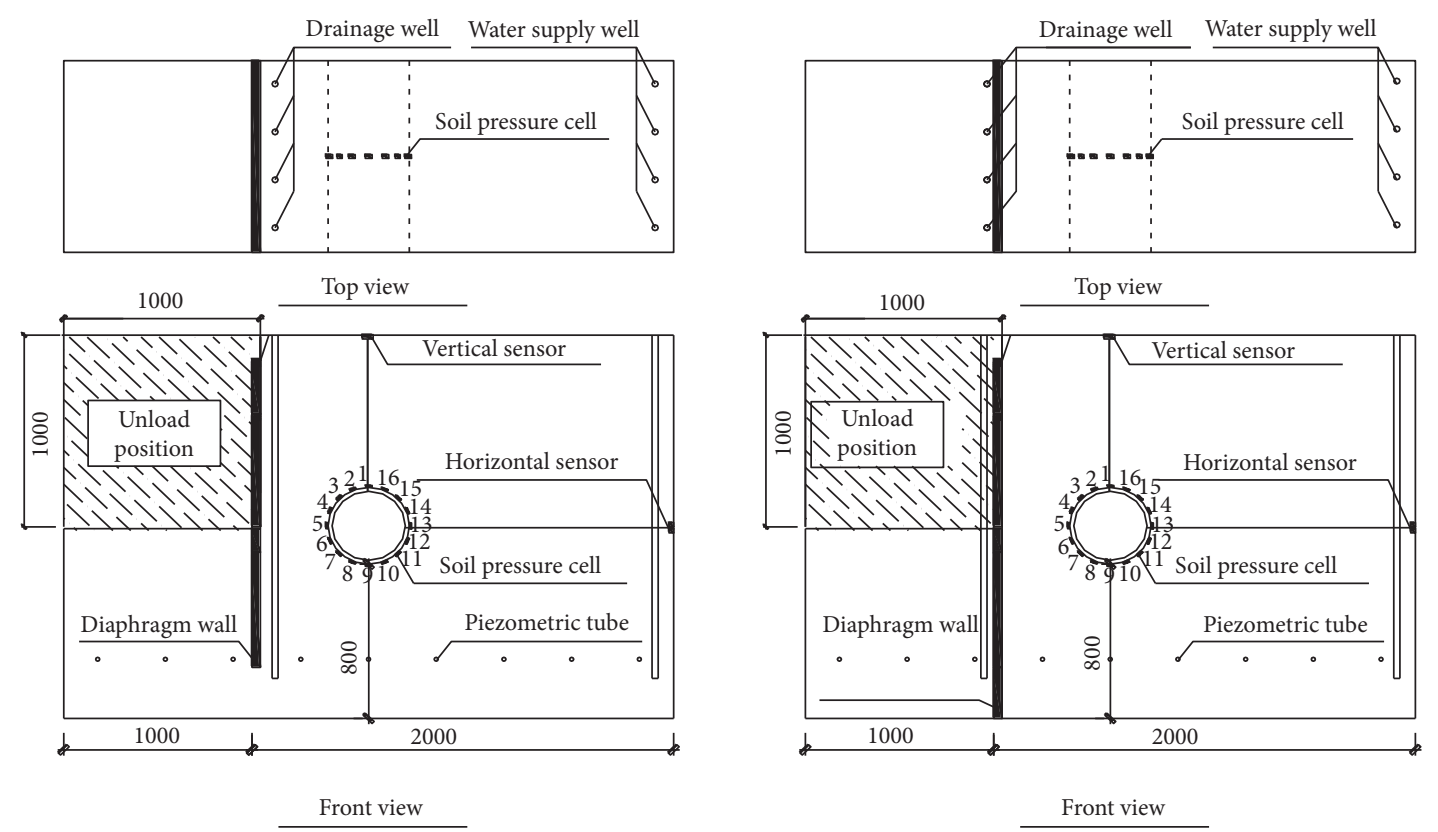

Figure 3: Schematic maps of test schemes: (a) scheme 1; (b) scheme 2.

TABLE 5: Model test process.

\begin{tabular}{lc}
\hline Step & Name of the condition \\
\hline 1 & Read the initial value \\
2 & Dewater \\
3 & Excavate to -133 mm depth \\
4 & Tension the first layer of anchor cable \\
5 & Excavate to $-266 \mathrm{~mm}$ depth \\
6 & Excavate to $-400 \mathrm{~mm}$ depth \\
7 & Tension the second layer of anchor cable \\
8 & Excavate to $-533 \mathrm{~mm}$ depth \\
9 & Excavate to $-666 \mathrm{~mm}$ depth \\
10 & Tension the third layer of anchor cable \\
11 & Excavate to -800 mm depth \\
12 & Excavate to -933 mm depth \\
13 & Excavate to -1000 mm depth \\
14 & Stay stationary after excavation completion \\
15 & Load the mat foundation \\
16 & Load the first layer of weights \\
17 & Load the second layer of weights \\
18 & Load the third layer of weights \\
19 & Load the fourth layer of weights \\
20 & Load the fifth layer of weights \\
21 & Load the sixth layer of weights \\
22 & Load the seventh layer of weights \\
23 & Stay stationary after load completion \\
24 & Groundwater recover to the initial level \\
25 & Stay stationary after groundwater recover \\
\hline
\end{tabular}

3.1. Numerical Model. To meet the boundary effect caused by the foundation pit excavation and the requirement of the seepage calculation area, the model calculation range was $X=220 \mathrm{~m}, Y=220 \mathrm{~m}$, and $Z=60 \mathrm{~m}$.

The upper surface of the model was free boundary, and the bottom was vertical displacement constraint. Each side of the model was displacement constraint in corresponding direction. The boundary conditions were consistent with the model test. To simulate the replenishment of the natural groundwater, the far side boundary of the foundation pit was set as the constant head. In scheme 1, the bottom boundary was set to be impermeable. In scheme 2 , the diaphragm wall was embedded in the impervious layer. Therefore, the clayey silt II was set as impermeable, and there is no groundwater in medium sand and pebbles.

In the model, the soil and the diaphragm wall were set as the solid element. The anchor cable and tunnel were set as the cable element and shell element, respectively. The meshing of the model is shown in Figure 6. The meshing of the excavation support structure and the tunnel is shown in Figure 7.

3.2. Model Parameters. In the numerical calculation, the MC model is commonly used in geotechnical problems. It can accurately simulate the soil under compression, but if it is used to simulate the soil properties of unloading engineering, it will get inaccurate results. The complex small strain model can more accurately reflect the various properties of soil and can get better prediction results in theory. However, there are many complex model parameters, which need high-quality tests and increase the difficulty of analysis. The modified cam-clay model (MCC) can reflect many vital features of soil, such as plasticity, strain hardening difference between loading and unloading stiffness, and stress-dependent stiffness [47]. It performs best in applications involving unloading conditions [48]. Therefore, the MCC was selected as the constitutive model of soil, and the elastic model was used for the mat foundation, the diaphragm wall, the tunnel, the building, and the anchor cable.

The MCC involves three main parameters, i.e., the slope of the compression curve $\lambda$, the slope of the rebound curve $\kappa$, and the slope of the critical state curve $M$. These strata parameters were based on the geological survey, which are 


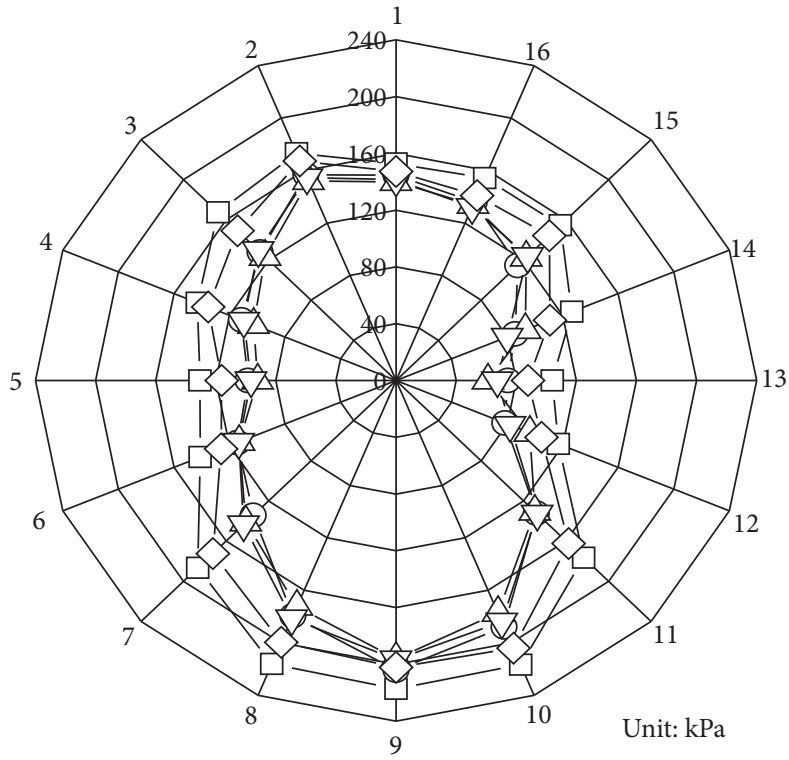

$\neg-$ Initial

-O- After dewatering $\triangle$ After excavation

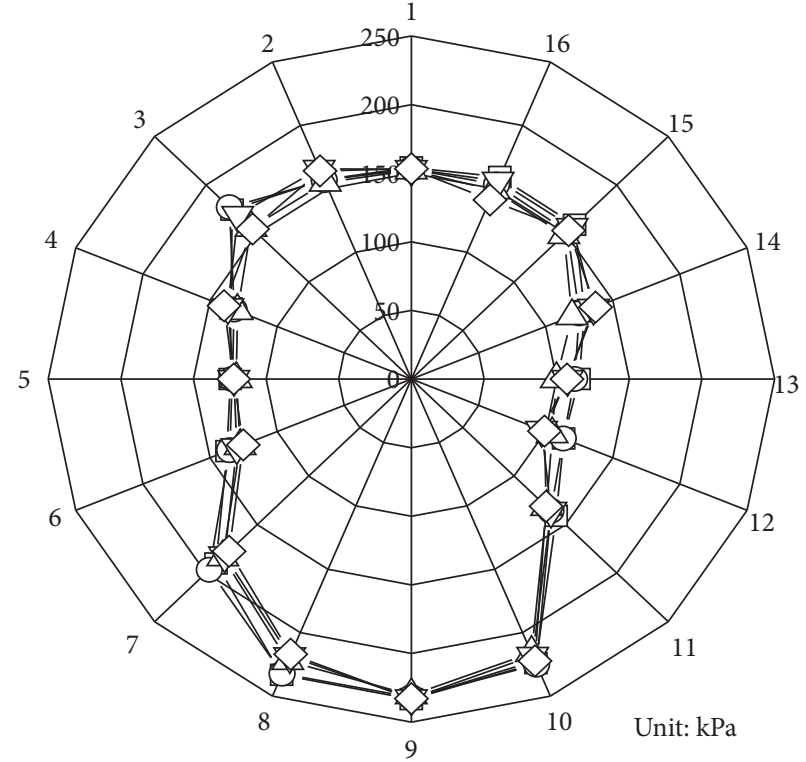

$-\square-$ Initial
$-\bigcirc-$ After dewatering
$-\triangle$ After excavation

$-\nabla$ After load

$\checkmark$ Groundwater recovery

(b)

(a)

FIGURE 4: Radar diagram of the surrounding earth pressure on the tunnel: (a) scheme 1; (b) scheme 2.

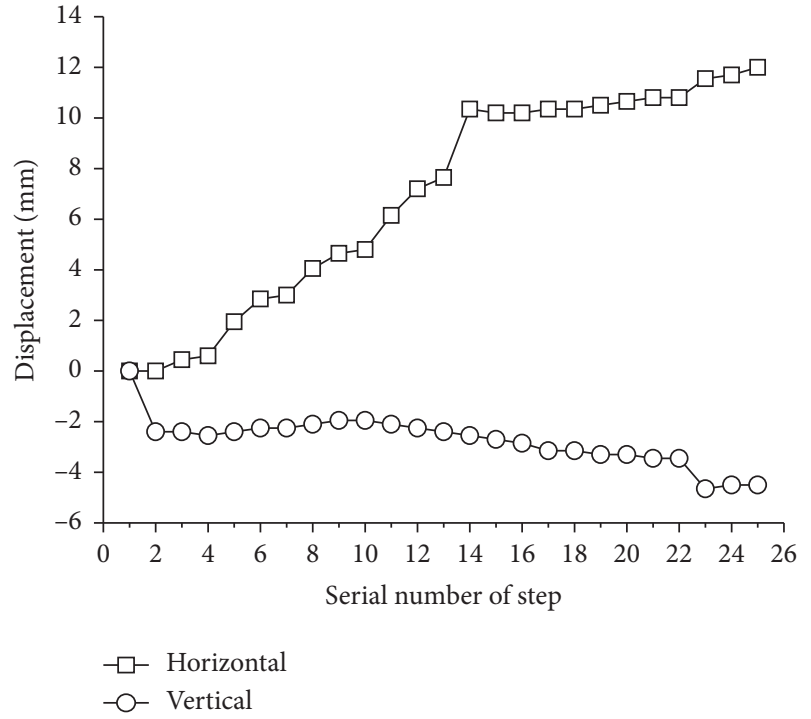

(a)

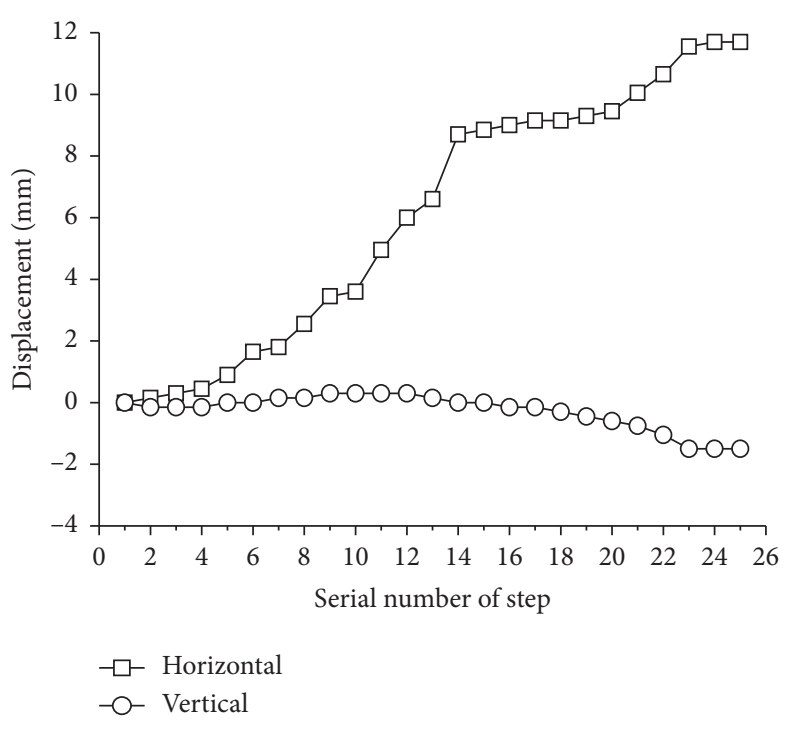

(b)

FIGURE 5: Time history of the tunnel displacement: (a) scheme 1; (b) scheme 2.

shown in Table 6 . The parameters of other structural elements are shown in Table 7.

3.3. Numerical Simulation Results and Analysis. The numerical simulation scheme corresponded to the model test. The numerical simulation process was basically consistent with that of the model test. The model size was the prototype size, which was the model test size multiplied by the similarity ratio of $15: 1$. The monitoring section took the middle section of the model. The layout of the measuring points and the rules of the positive and negative value of the tunnel displacement and earth pressure were the same as those in the model test.

3.3.1. Variation Law of Surrounding Earth Pressure of the Tunnel. The distribution of the surrounding earth pressure on the tunnel in the numerical simulation was similar to that 


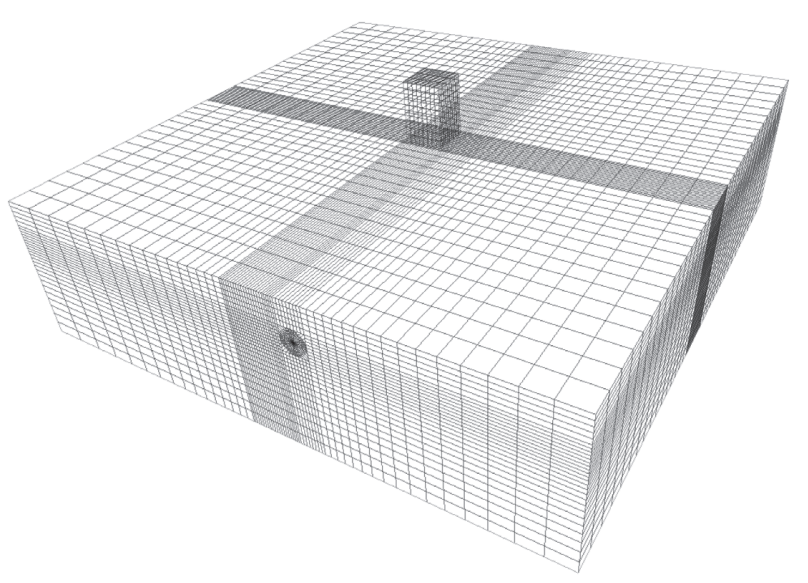

Figure 6: Meshing of the model.

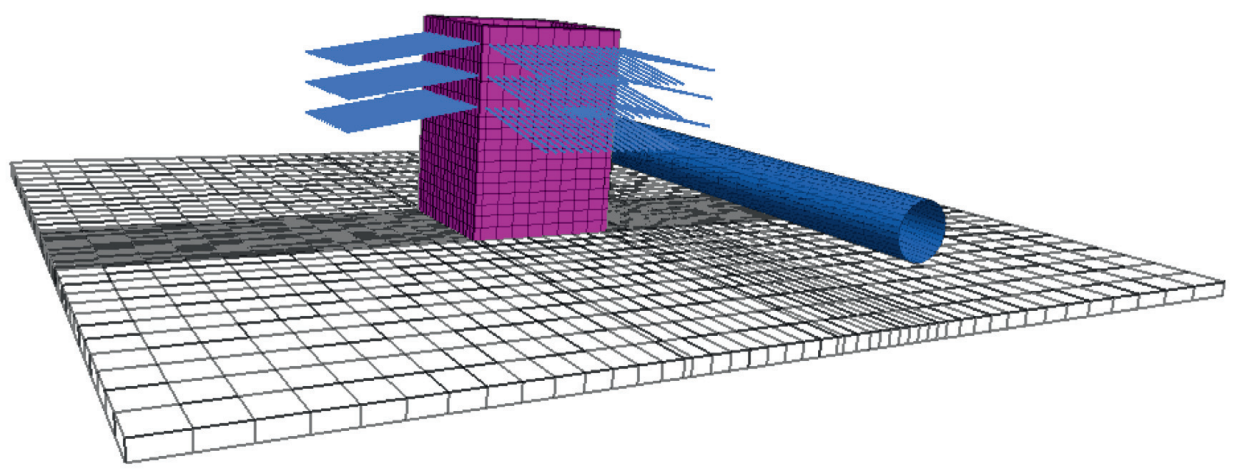

FIGURE 7: Meshing of the excavation support structure and the tunnel.

TABLE 6: Strata parameters in numerical simulation.

\begin{tabular}{lccc}
\hline Type of soil & Slope of the compression curve, $\lambda$ & Slope of the rebound curve, $\kappa$ & Slope of the critical state curve, $M$ \\
\hline Miscellaneous fill & 0.09 & 0.003 & 0.40 \\
Clayey silt I & 0.09 & 0.004 & 1.02 \\
Silty clay & 0.07 & 0.002 & 2.05 \\
Clayey silt II & 0.09 & 0.004 & 1.24 \\
Medium sand & 0.02 & 0.001 & 1.42 \\
Pebbles & 0.01 & 0.001 & 1.42 \\
\hline
\end{tabular}

TABLE 7: Major parameters of structural element.

\begin{tabular}{lccc}
\hline Type of element & Elastic modulus, $E(\mathrm{MPa})$ & Poisson's ratio, $v$ & Unit weight, $\gamma\left(\mathrm{kN} / \mathrm{m}^{3}\right)$ \\
\hline Diaphragm wall & $3.15 E+4$ & 0.2 & 25 \\
Mat foundation & $3.15 E+4$ & 0.2 & 25 \\
Lining segment & $3.45 E+4$ & 0.2 & 25 \\
Anchor wire & $2.10 E+5$ & 0.2 & 78 \\
\hline
\end{tabular}

in the model test, as shown in Figure 8. In scheme 1, after the foundation pit dewatering, the surrounding earth pressure on the tunnel decreased significantly. The maximum decrease value $(77.38 \mathrm{kPa})$ was located at measuring point 6 , which was $27.85 \%$ of the initial value. The decrease of the horizontal total stress (measuring point $5: 67.05 \mathrm{kPa}$ ) was much greater than that of the vertical total stress (measuring point $1: 15.13 \mathrm{kPa}$ ). After the foundation pit excavation, the surrounding earth pressure decreased unevenly, and the unloading amount near the unloading position (measuring point 2 5) was more significant. Among them, the unloading amount of measuring point 3 and measuring point 4 is $30.30 \%$ and $31.34 \%$. After the building loading, the surrounding earth pressure increased slightly. When the groundwater recovered to the initial state, the surrounding earth pressure increased. The maximum increase value 

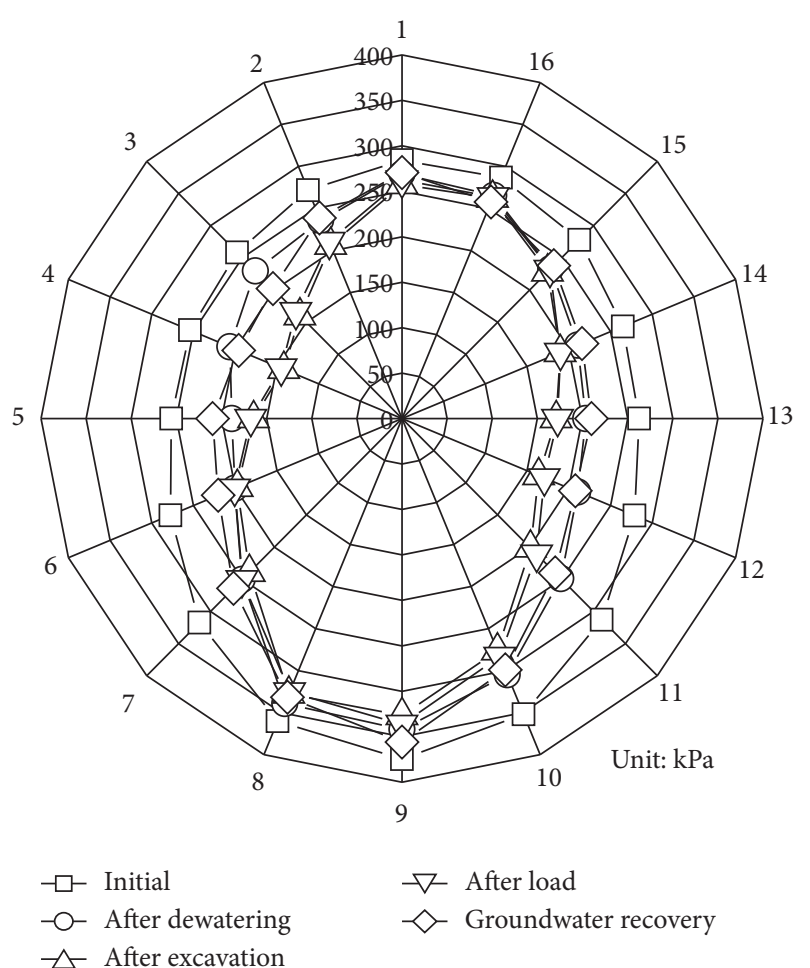

$\nabla$ After load

$\diamond$ Groundwater recovery

$\neg$ After excavation

(a)

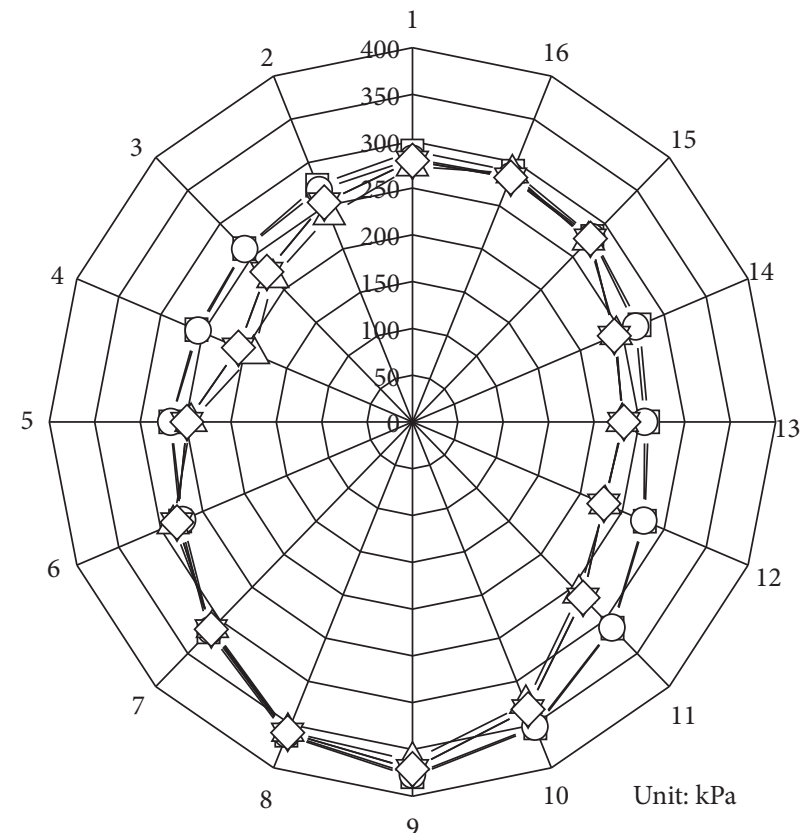

$-\square-$ Initial
$-\bigcirc-$ After dewatering

$\nabla-$ After load

$\diamond$ Groundwater recovery

(b)

FIGURE 8: Radar diagram of the surrounding earth pressure on the tunnel: (a) scheme 1; (b) scheme 2.

$(51.00 \mathrm{kPa})$ was located at measuring point 4 , which was $35.19 \%$ of the original value. The increase of the horizontal total stress (measuring point $5: 42.39 \mathrm{kPa}$ ) was much greater than that of the vertical total stress (measuring point 1: $8.30 \mathrm{kPa})$.

In scheme 2, after the foundation pit dewatering, the surrounding earth pressure on the tunnel almost did not change. The main reason is that the total stress of the soil inside the foundation pit decreased due to the dewatering inside the foundation pit, and the reduction was tiny, so the influence on the tunnel surrounding earth pressure was relatively small. After the completion of foundation pit excavation and building loading, the variation law of the surrounding earth pressure on the tunnel was similar to that in scheme 1 . When the dewatering stopped, the groundwater can only recover to the bottom of the building (the variation of water level is usually only about 1 meter), and the total stress of the soil in the foundation pit changed little, so the surrounding soil of the tunnel did not change much.

3.3.2. Variation Law of the Tunnel Displacement. There were more measure points in numerical simulation to reflect the characters of the tunnel displacement in more detail, as shown in Figures 9-12. In scheme 1, as shown in Figures 9 and 11, the tunnel settlement mainly occurred in the dewatering stage. The settlement of each measuring point is $4.90 \mathrm{~mm} \sim 5.57 \mathrm{~mm}$, accounting for $83.21 \% \sim 100.00 \%$ of the total settlement. In the building loading stage, the tunnel also had large settlement, accounting for $25.11 \% \sim 40.34 \%$ of the total settlement. The sum of settlement in these two stages was apparently more than $100.00 \%$, which was mainly because the tunnel rose a little during the excavation of foundation pit. Similarly, the tunnel also rose in the groundwater recovery stage, and the rise amount of each measuring point accounted for $-37.62 \% \sim-50.14 \%$ of the total settlement.

In the horizontal direction, during the construction process, the tunnel mainly moves towards the foundation pit. Among them, the tunnel displacement in the excavation stage accounts for the largest proportion. The displacement of each measuring point is $6.38 \mathrm{~mm} \sim 10.01 \mathrm{~mm}$, accounting for $82.77 \% \sim 86.30 \%$ of the maximum value. In the foundation pit dewatering and groundwater recovery stage, the tunnel has a small amount of displacement towards and away from the foundation pit, respectively. In the building loading stage, most of the measuring points move away from the foundation pit, but a small number of measuring points move towards the foundation pit.

The displacement radar diagram (Figure 11) showed that in the dewatering stage, the horizontal displacement of the measuring points in the upper half of the tunnel was slightly greater than that in the lower half, and the vertical displacement of the measuring points in the left side of the tunnel was slightly smaller than the right side. Therefore, the tunnel had an anticlockwise rotation or structural deformation. Under the same logic, in the excavation stage, the tunnel rose first and rotated clockwise and then gradually 


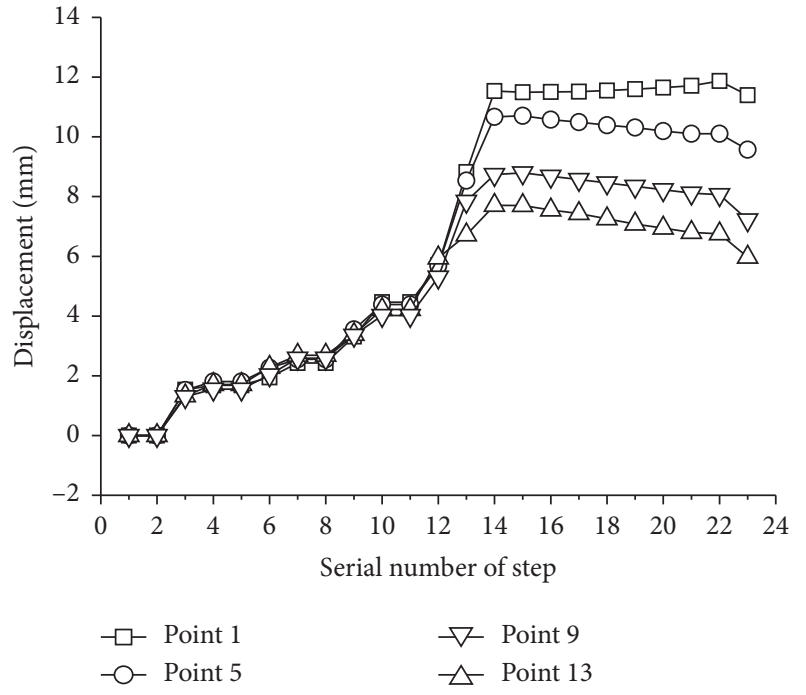

(a)

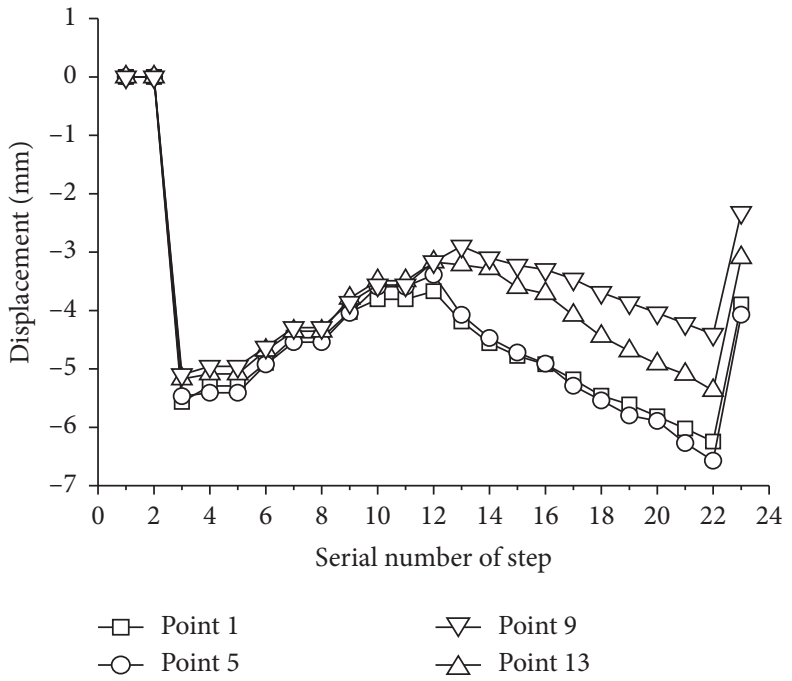

(b)

FIgURE 9: Time history of the tunnel displacement in scheme 1: (a) horizontal; (b) vertical.

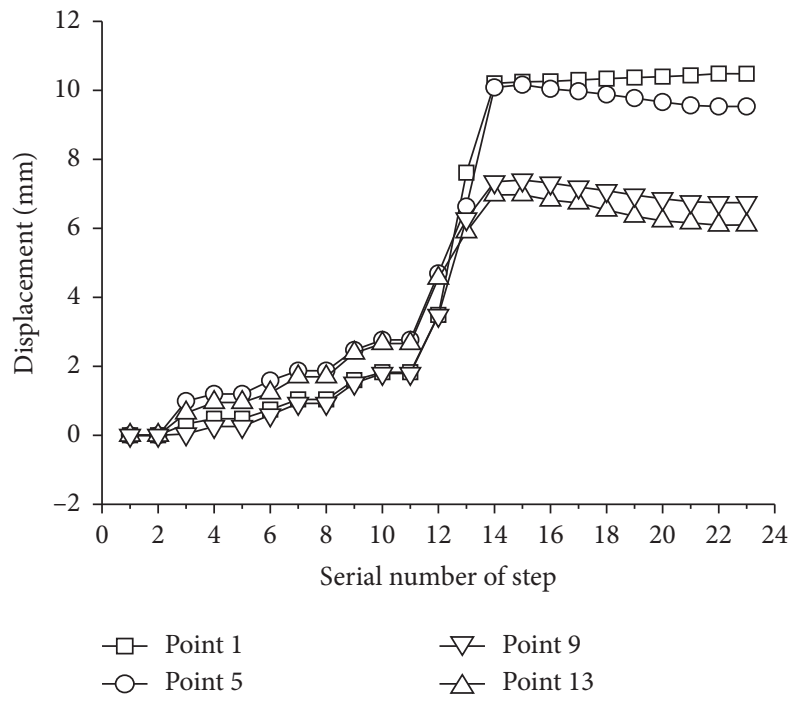

(a)

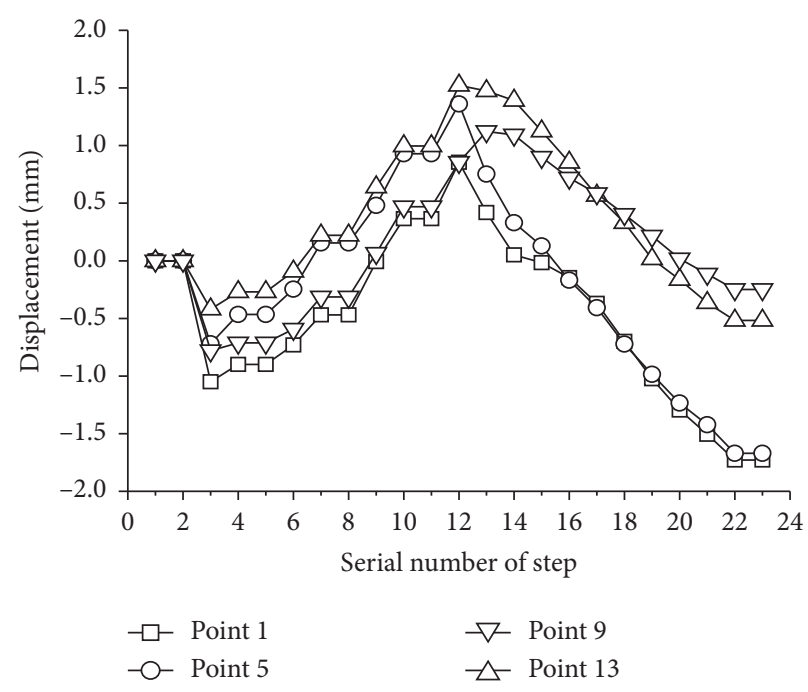

(b)

FIgURE 10: Time history of the tunnel displacement in scheme 2: (a) horizontal; (b) vertical.

sank, accompanied by anticlockwise rotation. In the loading stage, the tunnel continued to sink and rotated anticlockwise. When the groundwater recovered to the initial state, the tunnel rose and rotated clockwise.

In addition, after dewatering, the settlement of measuring points in the upper half was greater than that in the lower half, and the horizontal displacement value of measuring points in the left side was greater than that in the right side. Combined with Figure 8, the horizontal unloading amount was far greater than the vertical unloading amount. Therefore, the tunnel had vertical convergence and horizontal tension. Similarly, in the excavation stage, the tunnel had vertical convergence and horizontal tension. In the building loading stage and groundwater recovery stage, the change was not apparent.
In scheme 2, as shown in Figure 10, after dewatering, there was slight tunnel settlement and displacement towards the foundation pit. In the excavation and loading stage, the variation law of tunnel displacement was similar to that in scheme 1 . When the groundwater recovered to the initial state, the tunnel almost had no displacement.

3.4. Comparison between Model Test and Numerical Simulation. The model test preliminarily reveals the deformation law of tunnel under complex unloadingloading of adjacent soil. Based on the size of the engineering prototype, the results of the model test are further verified by numerical simulation. Although the 


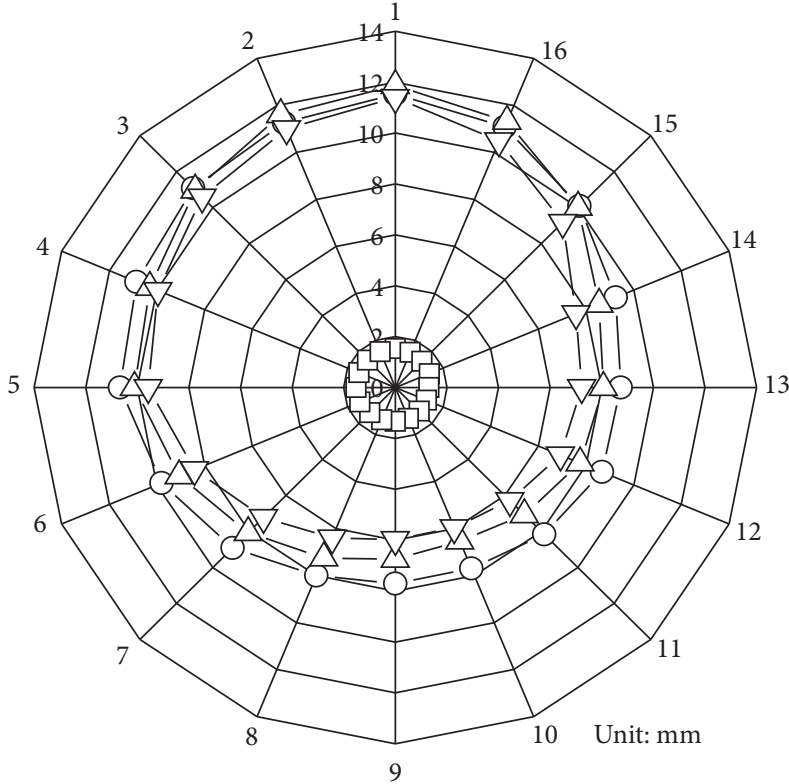

$\square-$ After dewatering

-O- After excavation

\begin{abstract}
$\nabla$ - Groundwater recovery $\triangle$ After load
\end{abstract}

(a)

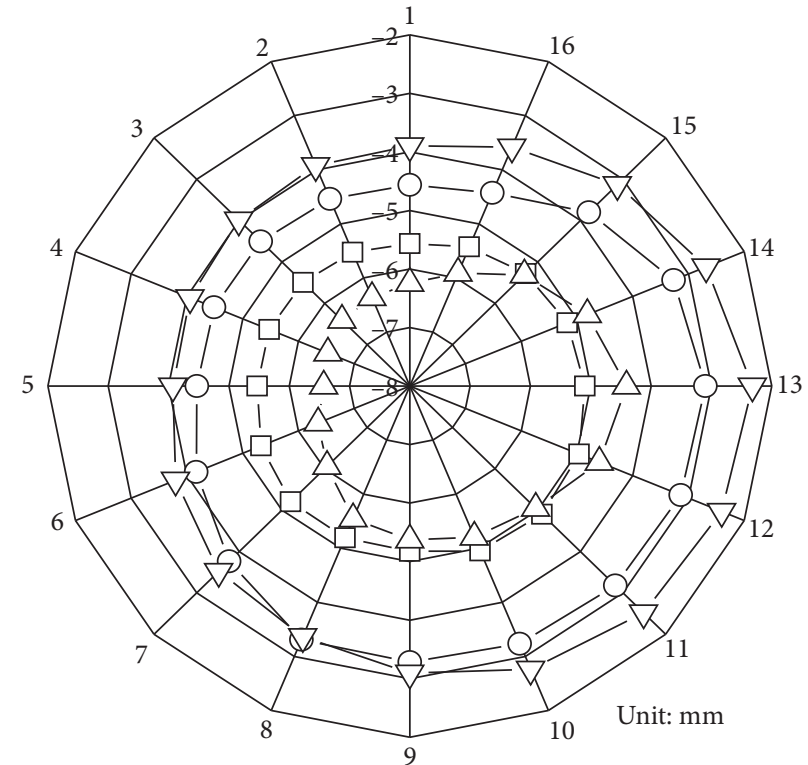

$-\square-$ After dewatering -O- After excavation

$-\nabla$ Groundwater recovery $\triangle$ After load

(b)

Figure 11: Radar diagram of the tunnel displacement in scheme 1: (a) horizontal; (b) vertical.

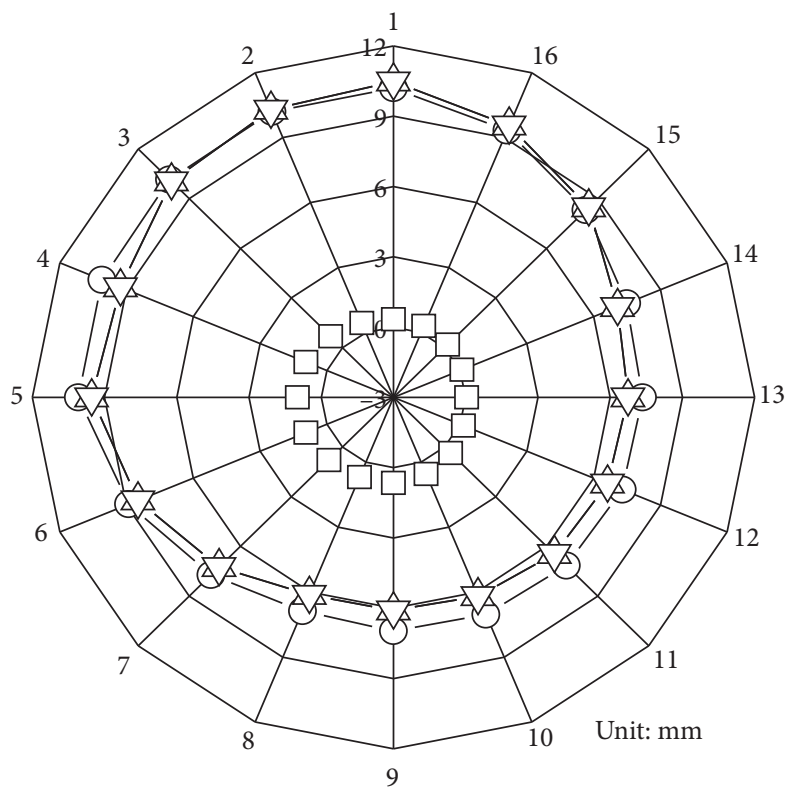

$\neg \square-$ After dewatering $-\mathrm{O}$ - After excavation $-\nabla$ Groundwater recovery $\triangle \bullet$ After load

(a)

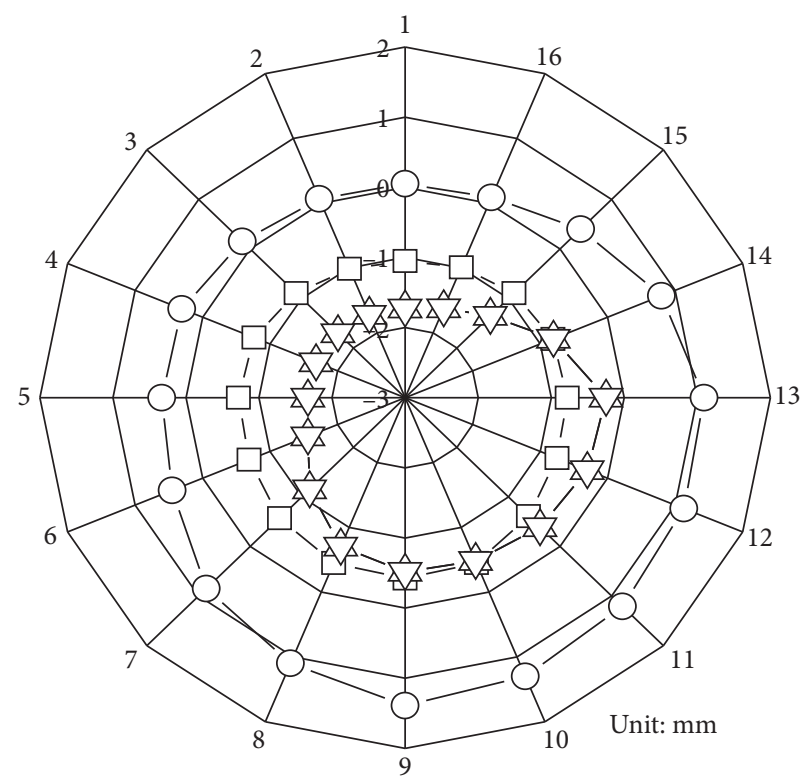

$-\square$ After dewatering
$-\bigcirc-$ After excavation

$\nabla$ Groundwater recovery $\triangle$ After load

(b)

FIGURE 12: Radar diagram of the tunnel displacement in scheme 1: (a) horizontal; (b) vertical. 
numerical values of the two methods are not entirely consistent, the change rules are the same, which proves the correctness of the model test and numerical simulation results. The mechanical mechanism of tunnel deformation in the complex construction process is analyzed as follows.

\section{Mechanical Mechanism of Tunnel Deformation}

According to the principle of effective stress, the total stress in soil is composed of effective stress on solid soil particles and pore water pressure on pore water, as shown in the following equation:

$$
\sigma=u+\sigma^{\prime}
$$

When discussing the change of effective stress after dewatering, it is often considered that the total stress $(\sigma)$ remains unchanged. After dewatering, the pore water pressure decreases to $0(u=0)$, so the effective stress $\left(\sigma^{\prime}\right)$ increases. But in fact, the change of groundwater level causes the change of total stress.

According to the simplified calculation schematic diagram (Figure 13), the total vertical stress, pore water pressure, effective stress, total horizontal stress, and stress increment at different locations before and after dewatering can be calculated, respectively, as shown in Tables 8-10.

In the process of dewatering, as shown in Figure 14, the water level gradually changes from I to II and finally to position III. As shown in Table 10, no matter which step the groundwater level changes to, as long as the soil is below the initial groundwater level at the beginning of dewatering, whether it is above the current groundwater level (point $A$ in Figure 13) or below it (point $B$ in Figure 13), the effective stress increment is positive. Simultaneously, at different positions of the same buried depth, $Z_{x}$ or $Z_{2}$ is different, and the effective stress increment is also different. Therefore, in the vertical direction, the soil beneath the tunnel produces uneven settlement due to uneven consolidation and compression. Then, the tunnel sinks and rotates anticlockwise. In the horizontal direction, the surrounding earth pressure on the right side of the tunnel is more significant than that on the left side, and the difference between the two sides makes the tunnel move towards the foundation pit. After dewatering, the vertical earth pressure on the tunnel decreases (because $\gamma-\gamma_{\text {sat }}$ is a negative value), and the horizontal surrounding earth pressure on the tunnel also decreases (because $K_{0}\left(\gamma-\gamma^{\prime}\right)-\gamma_{w}$ is a negative value), so the surrounding earth pressure on the tunnel in Figures 4(a) and 8 (a) changes much.

When the foundation pit is excavated, the earth pressure outside the foundation pit changes from static earth pressure to active earth pressure, manifested as horizontal unloading. The unloading amount decreases with the increase of the distance from the diaphragm wall of the foundation pit. Therefore, the tunnel moves towards the inner side of the foundation pit due to the pressure difference of the surrounding earth pressure on the horizontal sides.
Simultaneously, the diaphragm wall rises due to the rebound of the soil at the bottom of the foundation pit, which drives the deep soil to rise slightly together. In the horizontal direction, the earth pressure on both sides of the diaphragm wall is unbalanced, and the soil moves towards the foundation pit. Therefore, the tunnel in the deep position outside the pit moves towards the foundation pit along with the soil mass, as shown in steps 4 to 12 of Figures 9 and 10.

In addition to the abovementioned effects, horizontal unloading also makes the diaphragm wall move towards the foundation pit, which causes ground loss outside the pit and forms a settlement tank from the surface downward. The settlement value decreases with the increase of the depth, and the range of the settlement tank increases with the increase of the excavation depth of the foundation pit. When the tunnel is in the settlement tank, the tunnel settlement occurs with the soil, as shown in step 13 and step 14 of Figures 9 and 10.

When the foundation pit is excavated, because the displacement field outside the pit changes unevenly, the tunnel rotates while moving. The torsion direction changes with the vertical position of the tunnel relative to the bottom of the foundation pit.

When the building is loaded, the additional stress of the foundation diffuses to the surrounding of the foundation base. However, the diffusion is not uniform, so the soil outside the foundation pit produces uneven consolidation compression, and the tunnel sinks with torsion. Also, when the building is loaded, the surrounding earth pressure on the tunnel changes little; this can be inferred that the structural deformation of the tunnel is relatively small.

When the groundwater level is recovered, the total vertical stress of soil increases. Whether the calculation point is under the water level or not, the pore water pressure in the soil increases, and the effective stress decreases, and the soil rebounds. Therefore, the tunnel floats upward and rotates slightly clockwise due to the uneven rebound of the soil below. When the groundwater level is recovered to the initial water level, the vertical and horizontal earth pressure of the tunnel also increases.

\section{Discussion}

According to the research, the influence of different construction conditions on tunnel deformation can be obtained. In the future, some studies of the targeted protection measures can be carried out. It should be noted that although the tunnel displacements in the opposite direction in the vertical direction at different construction stages, it is unlikely to offset each other by shortening the construction time in the practical engineering. Therefore, it is necessary to set up protective measures to control tunnel settlement and rise at the same time in engineering.

The MMC model was used for numerical simulation in this paper. Although the MCC model is fully suitable for general engineering needs, as mentioned above, small strain model can more accurately reflect the various properties of 


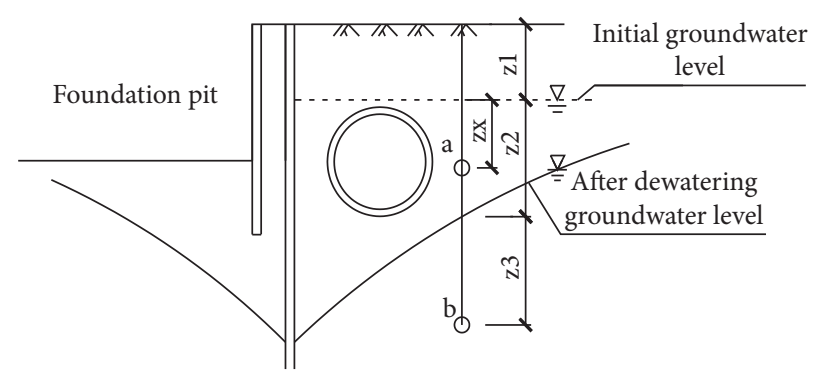

FIGURE 13: Simplified calculation schematic diagram.

TABLE 8: The stress of the calculation points before the dewatering.

\begin{tabular}{lcccc}
\hline Point & Total vertical stress & Pore water pressure & Effective stress & Total horizontal stress \\
\hline$A$ & $Z_{1} \gamma+Z_{x} \gamma_{\text {sat }}$ & $Z_{x} \gamma_{w}$ & $Z_{1} \gamma+Z_{x} \gamma^{\prime}$ & $K_{0} Z_{1} \gamma+K_{0} Z_{x} \gamma^{\prime}+Z_{x} \gamma_{w}$ \\
$B$ & $Z_{1} \gamma+\left(Z_{2}+Z_{3}\right) \gamma_{\text {sat }}$ & $\left(Z_{2}+Z_{3}\right) \gamma_{w}$ & $Z_{1} \gamma+\left(Z_{2}+Z_{3}\right) \gamma^{\prime}$ & $K_{0} Z_{1} \gamma+K_{0}\left(Z_{2}+Z_{3}\right) \gamma^{\prime}+\left(Z_{2}+Z_{3}\right) \gamma_{w}$ \\
\hline
\end{tabular}

TABLE 9: The stress of the calculation points after the dewatering.

\begin{tabular}{lcccc}
\hline Point & Total vertical stress & Pore water pressure & Effective stress & Total horizontal stress \\
\hline$A$ & $\left(Z_{1}+Z_{x}\right) \gamma$ & 0 & $\left(Z_{1}+Z_{x}\right) \gamma$ & $K_{0}\left(Z_{1}+Z_{x}\right) \gamma$ \\
$B$ & $\left(Z_{1}+Z_{2}\right) \gamma+Z_{3} \gamma_{\text {sat }}$ & $Z_{3} \gamma_{w}$ & $\left(Z_{1}+Z_{2}\right) \gamma+Z_{3} \gamma^{\prime}$ & $K_{0}\left(Z_{1}+Z_{2}\right) \gamma+K_{0} Z_{3} \gamma^{\prime}+Z_{3} \gamma_{w}$ \\
\hline
\end{tabular}

TABLE 10: The stress increment of the calculation points after the dewatering.

\begin{tabular}{lcccc}
\hline Point & Total vertical stress & Pore water pressure & Effective stress & Total horizontal stress \\
\hline$A$ & $Z_{x}\left(\gamma-\gamma_{\text {sat }}\right)$ & $-Z_{x} \gamma_{w}$ & $Z_{x}\left(\gamma-\gamma^{\prime}\right)$ & $Z_{x}\left[K_{0}\left(\gamma-\gamma^{\prime}\right)-\gamma_{w}\right]$ \\
$B$ & $Z_{2}\left(\gamma-\gamma_{\text {sat }}\right)$ & $-Z_{2} \gamma_{w}$ & $Z_{2}\left(\gamma-\gamma^{\prime}\right)$ & $Z_{2}\left[K_{0}\left(\gamma-\gamma^{\prime}\right)-\gamma_{w}\right]$ \\
\hline
\end{tabular}

where $\gamma=$ natural gravity of soil, $\gamma_{\text {sat }}=$ saturated unit weight of soil, $\gamma^{\prime}=$ floating soil mass, $\gamma_{w}=$ the gravity of water, and $K_{0}=$ lateral pressure coefficient.

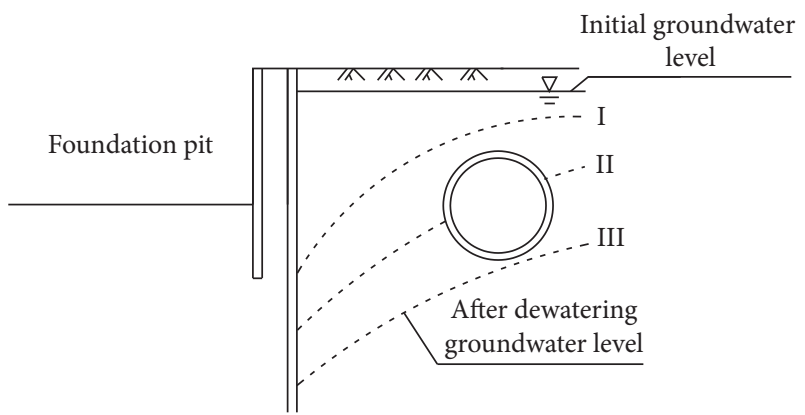

FIGURE 14: Variation of water level during dewatering.

soil. Therefore, the small strain model can be used for further research in the future.

The model test and the simulation calculation have their advantages, but both of them need complex processes of establishing test model. In the future, the analytical calculation method can be used to study, and the results can be obtained more quickly.

\section{Conclusions}

Two large scale model tests and corresponding numerical simulations have been conducted to analyze the influence of dewatering, foundation pit excavation, building loading, and groundwater recovery on the adjacent tunnel. The variation law of surrounding earth pressure and deformation of the existing tunnel and its mechanical mechanism under these complex unloading and loading effects were discussed. The achievements of the present study are as follows:

(1) In the nonisolated dewatering unloading-loading mode, the decrease or rise of the groundwater level significantly reduces (maximum 27.85\%) or increases (maximum 35.19\%) the surrounding earth pressure of the tunnel. The decrease or increase of the horizontal total stress was much greater than that of the vertical total stress. The massive uneven change of the surrounding earth pressure further leads to the deformation of the tunnel structure. However, in the isolated dewatering unloading-loading mode, the change of groundwater has little effect on the tunnel.

(2) In the nonisolated dewatering unloading-loading mode, the tunnel settlement mainly occurs in the dewatering stage and the building loading stage, accounting for $83.21 \%-100.00 \%$ and $25.11 \%-40.34 \%$ of the total settlement, respectively. The total amount is more than $100 \%$, which is mainly due to the rise of the tunnel during the foundation pit excavation and the groundwater recovery.

(3) In the two modes, the horizontal displacement of the tunnel is mainly concentrated in the foundation pit excavation stage. The displacement value of each 
measuring point is greater than $6.00 \mathrm{~mm}$, accounting for more than $80 \%$ of the maximum displacement. Therefore, it is necessary to mainly control the displacement of excavation stage.

(4) During the construction process, torsion and structural deformation occur in the tunnel. Among them, the structure deformation is large in the foundation pit excavation stage, which needs to be focused on in some projects with strict structural deformation control.

(5) After the excavation of the foundation pit, the surrounding environment continues to be affected, so the construction interval between the foundation pit excavation and building loading should be shortened as far as possible.

\section{Data Availability}

The data used to support the findings of this study are available from the corresponding author upon request.

\section{Conflicts of Interest}

The authors declare that they have no conflicts of interest.

\section{Acknowledgments}

The authors appreciate the support from the Science and Technology Project of Ministry of Housing and Urban-Rural development of the People's Republic of China (Grant no. 2020-K-139) and the National Natural Science of Foundation of China (Grant no. 51578023).

\section{References}

[1] G. Zheng and S.-W. Wei, "Numerical analyses of influence of overlying pit excavation on existing tunnels," Journal of Central South University of Technology, vol. 15, no. S2, pp. 69-75, 2008.

[2] J. Shi, C. W. W. Ng, and Y. Chen, "Three-dimensional numerical parametric study of the influence of basement excavation on existing tunnel," Computers and Geotechnics, vol. 63, pp. 146-158, 2015.

[3] B. A. Reza and G. Vojtech, "3D numerical parametric study of the influence of open-pit mining sequence on existing tunnels," International Journal of Mining Science and Technology, vol. 27, pp. 459-466, 2017.

[4] W. D. Wang, J. Shen, Q. P. Weng et al., "Analysis and countermeasures of influence of excavation on adjacent tunnels," Chinese Journal of Geotechnical Engineering, vol. 28, pp. 1340-1345, 2006, in Chinese.

[5] F. Wang, D. M. Zhang, H. H. Zhu et al., "Impact of overhead excavation on an existing shield tunnel: field monitoring and a full 3D finite element analysis," Computers, Materials and Continua, vol. 34, pp. 63-81, 2013.

[6] C.-T. Chang, C.-W. Sun, S. W. Duann, and R. N. Hwang, "Response of a taipei rapid transit system (TRTS) tunnel to adjacent excavation," Tunnelling and Underground Space Technology, vol. 16, no. 3, pp. 151-158, 2001.
[7] R. N. Hwang, S. W. Duann, K. H. Cheng et al., "Damages to metro tunnels due to adjacent excavations," in Proceeding of the TC302 Symposium, pp. 83-88, Osaka, Japan, July 2011.

[8] C. Shi, C. Cao, M. Lei, L. Peng, and H. Ai, "Effects of lateral unloading on the mechanical and deformation performance of shield tunnel segment joints," Tunnelling and Underground Space Technology, vol. 51, pp. 175-188, 2016.

[9] G. Zheng, S. W. Wei, S. Y. Peng et al., "Centrifuge modeling of the influence of basement excavation on existing tunnels," in Proceedings of the International Conference on Physical Modelling in Geotechnics, pp. 523-527, Zurich, Switzerland, July 2010.

[10] C. W. W. Ng, J. Shi, and Y. Hong, "Three-dimensional centrifuge modelling of basement excavation effects on an existing tunnel in dry sand," Canadian Geotechnical Journal, vol. 50, no. 8, pp. 874-888, 2013.

[11] X. Huang, H. Huang, and D. Zhang, "Centrifuge modelling of deep excavation over existing tunnels," Proceedings of the Institution of Civil Engineers-Geotechnical Engineering, vol. 167, no. 1, pp. 3-18, 2014.

[12] P. Li, S.-J. Du, X.-F. Ma, Z.-Y. Yin, and S.-L. Shen, "Centrifuge investigation into the effect of new shield tunnelling on an existing underlying large-diameter tunnel," Tunnelling and Underground Space Technology, vol. 42, pp. 59-66, 2014.

[13] J. W. Shi, C. Ding, C. W. W. Ng et al., "Effects of overconsolidation ratio on tunnel responses due to overlying basement excavation in clay," Tunnelling and Underground Space Technology, vol. 97, Article ID 103247, 2020.

[14] Y.-G. Tang and G. T.-C. Kung, "Investigating the effect of soil models on deformations caused by braced excavations through an inverse-analysis technique," Computers and Geotechnics, vol. 37, no. 6, pp. 769-780, 2010.

[15] X. Huang, H. F. Schweiger, and H. Huang, "Influence of deep excavations on nearby existing tunnels," International Journal of Geomechanics, vol. 13, no. 2, pp. 170-180, 2013.

[16] G. Zheng, Y. Du, X. Cheng, Y. Diao, X. Deng, and F. Wang, "Characteristics and prediction methods for tunnel deformations induced by excavations," Geomechanics and Engineering, vol. 12, no. 3, pp. 361-397, 2017.

[17] G. Zheng, X. Y. Yang, H. Z. Zhou et al., "A simplified prediction method for evaluating tunnel displacement induced by laterally adjacent excavations," Computers and Geotechnics, vol. 95, pp. 119-128, 2017.

[18] M.-G. Li, J.-J. Chen, J.-H. Wang, and Y.-F. Zhu, "Comparative study of construction methods for deep excavations above shield tunnels," Tunnelling and Underground Space Technology, vol. 71, pp. 329-339, 2018.

[19] J. Shi, X. Zhang, Y. Chen, and L. Chen, "Numerical parametric study of countermeasures to alleviate basement excavation effects on an existing tunnel," Tunnelling and Underground Space Technology, vol. 72, pp. 145-153, 2018.

[20] J. Shi, C. W. W. Ng, and Y. Chen, "A simplified method to estimate three-dimensional tunnel responses to basement excavation," Tunnelling and Underground Space Technology, vol. 62, pp. 53-63, 2017.

[21] J. Shi, Z. Fu, and W. Guo, "Investigation of geometric effects on three-dimensional tunnel deformation mechanisms due to basement excavation," Computers and Geotechnics, vol. 106, pp. 108-116, 2019.

[22] J.-F. Zhang, J.-J. Chen, J.-H. Wang, and Y.-F. Zhu, "Prediction of tunnel displacement induced by adjacent excavation in soft soil," Tunnelling and Underground Space Technology, vol. 36, pp. 24-33, 2013. 
[23] Z. Zhang, M. Huang, and W. Wang, "Evaluation of deformation response for adjacent tunnels due to soil unloading in excavation engineering," Tunnelling and Underground Space Technology, vol. 38, pp. 244-253, 2013.

[24] R. Liang, T. Xia, M. Huang, and C. Lin, "Simplified analytical method for evaluating the effects of adjacent excavation on shield tunnel considering the shearing effect," Computers and Geotechnics, vol. 81, pp. 167-187, 2017.

[25] R. Liang, W. Wu, F. Yu, G. Jiang, and J. Liu, "Simplified method for evaluating shield tunnel deformation due to adjacent excavation," Tunnelling and Underground Space Technology, vol. 71, pp. 94-105, 2018.

[26] J. W. Liu, C. H. Shi, M. F. Lei et al., "Improved analytical method for evaluating the responses of a shield tunnel to adjacent excavations and its application," Tunnelling and Underground Space Technology, vol. 98, Article ID 103339, 2020.

[27] D. M. Zhang, X. C. Xie, Z. L. Li et al., "Simplified analysis method for predicting the influence of deep excavation on existing tunnels," Computers and Geotechnics, vol. 121, Article ID 103477, 2001.

[28] M. Devriendt, L. Doughty, P. Morrison, and A. Pillai, "Displacement of tunnels from a basement excavation in London," Proceedings of the Institution of Civil Engineers - Geotechnical Engineering, vol. 163, no. 3, pp. 131-145, 2010.

[29] M. Khoiri and C.-Y. Ou, "Evaluation of deformation parameter for deep excavation in sand through case histories," Computers and Geotechnics, vol. 47, pp. 57-67, 2013.

[30] B. Simpson and P. J. Vardanega, "Results of monitoring at the British Library excavation," Proceedings of the Institution of Civil Engineers-Geotechnical Engineering, vol. 167, no. 2, pp. 99-116, 2014.

[31] F. Y. Meng, R. P. Chen, H. N. Wu et al., "Observed behaviors of a long and deep excavation and collinear underlying tunnels in Shenzhen granite residual soil," Tunnelling and Underground Space Technology, vol. 103, Article ID 103504, 2020.

[32] B. Liu, D. W. Zhang, C. Yang et al., "Long-term performance of metro tunnels induced by adjacent large deep excavation and protective measures in Nanjing silty clay," Tunnelling and Underground Space Technology, vol. 95, Article ID 103147, 2020.

[33] H. Sun, Y. Chen, J. Zhang, and T. Kuang, "Analytical investigation of tunnel deformation caused by circular foundation pit excavation," Computers and Geotechnics, vol. 106, pp. 193-198, 2019.

[34] H. S. Sun, L. W. Wang, S. W. Chen et al., "A precise prediction of tunnel deformation caused by circular foundation pit excavation," Applied Sciences, vol. 9, Article ID 2275, 2019.

[35] C. W. W. Ng, J. Shi, D. Mašín, H. Sun, and G. H. Lei, "Influence of sand density and retaining wall stiffness on threedimensional responses of tunnel to basement excavation," Canadian Geotechnical Journal, vol. 52, no. 11, pp. 1811-1829, 2015.

[36] R. Chen, F. Meng, Z. Li, Y. Ye, and J. Ye, "Investigation of response of metro tunnels due to adjacent large excavation and protective measures in soft soils," Tunnelling and Underground Space Technology, vol. 58, pp. 224-235, 2016.

[37] H. S. Sun and W. B. Sun, "Effect of soil reinforcement on tunnel deformation as a result of stress relief," Applied Sciences, vol. 9, Article ID 1420, 2019.

[38] M. Dolezalova, "Tunnel complex unloaded by a deep excavation," Computers and Geotechnics, vol. 28, pp. 469-493, 2001.
[39] H. N. Wang, X. P. Chen, M. J. Jiang, F. Song, and L. Wu, "The analytical predictions on displacement and stress around shallow tunnels subjected to surcharge loadings," Tunnelling and Underground Space Technology, vol. 71, pp. 403-427, 2018.

[40] C. Chen, S. Pei, and J. Jiao, "Land subsidence caused by groundwater exploitation in Suzhou City, China," Hydrogeology Journal, vol. 11, no. 2, pp. 275-287, 2003.

[41] J.-C. Chai, S.-L. Shen, H.-H. Zhu, and X.-L. Zhang, "Land subsidence due to groundwater drawdown in Shanghai," Géotechnique, vol. 54, no. 2, pp. 143-147, 2004.

[42] Y. S. Xu, H. N. Wu, Z. F. Wang et al., "Dewatering induced subsidence during excavation in a Shanghai soft deposit," Environmental Earth Sciences, vol. 76, Article ID 351, 2017.

[43] D. S. Liyanapathirana and R. Nishanthan, "Influence of deep excavation induced ground movements on adjacent piles," Tunnelling and Underground Space Technology, vol. 52, pp. 168-181, 2016.

[44] H. Zhuang, J. Fu, X. Yu, S. Chen, and X. Cai, "Earthquake responses of a base-isolated structure on a multi-layered soft soil foundation by using shaking table tests," Engineering Structures, vol. 179, no. 15, pp. 79-91, 2019.

[45] E. Fumagalli, Statical and Geomechanical Models, Springer, New York, USA, 1973.

[46] J. Wang, Y. Deng, R. Ma et al., "Model test on partial expansion in stratified subsidence during foundation pit dewatering," Journal of Hydrology, vol. 557, pp. 489-508, 2018.

[47] Z. H. Xu and W. D. Wang, "Selection of soil constitutive models for numerical analysis of deep excavations in close proximity to sensitive properties," Rock and Soil Mechanics, vol. 31, pp. 258-264, 2010.

[48] R. B. J. Brinkgreve, "Selection of soil models and parameters for geotechnical engineering application," in Proceedings of the Geo-Frontier Conference, pp. 69-98, Austin, TX, USA, January 2005. 